\title{
National Survey of Drug Information Centers Practice in Saudi Arabia: Medication-Use Evaluation System at Ministry of Health Hospitals
}

\author{
Yousef Ahmed Alomi ${ }^{1 *}$, Saeed Jamaan Alghamdi ${ }^{2}$ and Radi Abdullah Alattyh ${ }^{2}$
}

${ }^{1} \mathrm{Head}$, National Clinical Pharmacy and Pharmacy Practice, Head, Pharmacy R \& D Administration, Ministry of Health, Riyadh, Saudi Arabia

${ }^{2}$ General Administration of Pharmaceutical Care, Ministry of Health, Riyadh, Saudi Arabia

\begin{abstract}
Objective: To explore National Survey of Drug Information Centers practice in Saudi Arabia: With emphasis on Medication-Use Evaluation system at Ministry of Health hospitals in Saudi Arabia.

Methods: It is a cross-sectional four months national survey of drug information services at $\mathrm{MOH}$. It contained ten domains with 181 questions designed by the authors. It derived from Internal Pharmaceutical Federation (FIP), American Society of Health-System Pharmacists best practice guidelines. This survey distributed to forty hospital pharmacies that run drug information services. In this study, the domain Medication-Use Evaluation System explored and analyzed. It consisted of eight questions about the written policy and procedure and application methods for Medication-Use Evaluation system in the drug information centers. All analysis is done through survey monkey system.
\end{abstract}

Results: The survey distributed to forty-five of hospitals, the response rate, was $40(88.88 \%)$ hospitals. Of those, developedscreening mechanism (indicators) for comprehensive surveillance of the medications use system existed in 24 (60\%) hospitals involved $25 \%-100 \%$ the elements. Establish criteria, guidelines, treatment protocols and standards of care for specific medications and medications use processes found in $26(65 \%)$ hospitals applied $25 \%-100 \%$ the elements. Establish mechanisms for timely communication among health-care professionals exist in $23(57.5 \%)$ hospitals found used $25 \%-100 \%$ the elements. Initiate the use of MUE criteria, guidelines, treatment protocols and standards of care in the medication-use process exist in 24 (60\%) hospitals found applied $25 \%-100 \%$ the elements. Regularly assesses the effectiveness of the MUE process itself and makes needed improvements exist in $24(60 \%)$ hospitals found used $25 \%-100 \%$ the elements.

Conclusion: There was an inadequate implementation of Medication-Use Evaluation in drug information centers practice. Establishing strategic planning for Medication-Use Evaluation system, choosing the high-cost and high-risk medications and educate drug information pharmacist. It improves Medication-Use Evaluation practice, prevents misuse of medicines, prevents drug misadventure and avoids the unnecessary additional cost.

Keywords: Drug information centers; Drug utilization evaluation; Ministry of health; Saudi Arabia

Abbreviations: KSA: Kingdom of Saudi Arabia; MOH: Ministry of Health; DIC: Drug Information Centers; IDS: Investigational Drug Services; PPS: Professional Publications Services

\section{Introduction}

The drug utilization evaluation (DUE) or medication utilization evaluation (MUE) is one the famous tool used to follow up drug therapy monitoring, measure the adherence to the guidelines and protocol for diseases management and retrospective analysis of drug-related problems. The program well described by American Society of Health-System Pharmacist (ASHP) and Society of Hospital Pharmacists of Australia (SHPA) since a long time [1,2]. The drug utilization evaluation required for hospital accreditation from national and international accreditation agencies [3,4]. Several studies conducted in the kingdom of Saudi Arabia for multiple medications. The studies done by alomi and his colleagues showed poor adherence to therapeutic Vancomycin guidelines and missing Aminoglycoside monitoring [5-7], in addition to unnecessary cost burden to the healthcare system of Albumin and Immunoglobulin $[8,9]$. Most of the local or international study of drug information center not included detail about drug utilization evaluation system [10]. In addition to the group of drug information centers or network did not contain detail manner of medication utilization evaluation [11-16]. There insufficient studies about that and the authors not familiar with local published investigated in Saudi Arabia or Gulf and Middle East countries [17,18]. Also, it seldom finds even overall the worldwide. The objective of the study to explore drug utilization evaluation system implementation at drug information centers in Saudi Arabia.

\section{Methods}

It is a cross-sectional four months national survey of Drug Information Services at MOH. It contained ten domains; Leadership and Practice Management, Medication Addition and Deletion System, Hospital Formulary System, Medication Safety System, Professional and Public Education. The Evidence-Based Medicine-Therapeutics Guidelines (EBM-TG), Medication-Use Evaluation (MUE), Pharmacoeconomics System, Investigational Drug Services (IDS) and Professional Publications Services (PPPS) and Ethical and Legal Issue. It consisted of 181 questions designed by the authors. It drove from Internal Pharmaceutical Federation (FIP), American Society of Health-System Pharmacists best practice guidelines, the international standard of Joint Commission of Hospital Accreditation. In addition to the local standards of Saudi center of Health Care Accreditation and Minimum Standards of Drug Information Centers in Saudi Arabia [3,4,19-21]. This survey distributed to forty-five hospital pharmacies that run drug information services. The information of hospitals services from extensive records of General Administration

*Corresponding author: Yousef Ahmed Alomi, Head, National Clinical Pharmacy and Pharmacy Practice, Head, Pharmacy R \& D Administration, Ministry of Health, P.O. BOX 100, Riyadh 11392, Saudi Arabia, Tel: +966504417712; E-mail: yalomi@gmail.com

Received: October 17, 2017; Accepted October 25, 2017; Published November 01, 2017

Citation: Alomi YA, Alghamdi SJ, Alattyh RA (2017) National Survey of Drug Information Centers Practice in Saudi Arabia: Medication-Use Evaluation System at Ministry of Health Hospitals. J Pharmacovigil 5: 245. doi:10.4172/2329-6887.1000245

Copyright: (C 2017 Alomi YA, et al. This is an open-access article distributed under the terms of the Creative Commons Attribution License, which permits unrestricted use, distribution, and reproduction in any medium, provided the original author and source are credited. 
of Pharmaceutical Care. In this study, the domain Medication-Use Evaluation System explored and analyzed. It consisted of thirteen questions as follows: Established organizational authority for the MUE process and identify responsible individuals and groups, developed screening mechanism (indicators) for comprehensive surveillance of the medication use system. Set priorities for in-depth analysis of important aspects of medication use, Inform healthcare professionals in the practice settings about the objectives and expected benefits of the MUE process. Establish criteria, guidelines, treatment protocols and standards of care for specific medications and medications use processes. Educate health-care professionals to promote the use of criteria, guidelines, treatment protocols and standards of care. Establish mechanisms for timely communication among health-care professionals, initiate the use of MUE criteria, guidelines, treatment protocols and standards of care in the medication-use process, Develop and implement plans for improvement of the medications use the method based on MUE findings and assess the effectiveness of action taken and document improvements. Incorporate improvements into criteria, guidelines, treatment protocols and standards of care when indicated, Repeat the cycle of planning, evaluating and taking action for ongoing improvements in medications use processes Repeat the cycle of planning, evaluating and taking action for ongoing improvements in medications use methods. Regularly assesses the effectiveness of the MUE process itself and makes needed improvements exist. The results analyzed by survey monkey system.

\section{Results}

The survey distributed to 45 of hospitals, the response rate, was 40 $(88.88 \%)$ hospitals. Of that $35 \%$ large hospitals, $37.5 \%$ medium size hospitals, $17.5 \%$ small size hospitals and $10 \%$ National and Regional Drug Information Centers. OF those, fifteen hospitals only accredited by CIBAHI and eight hospitals only accredited by Joint Commission while none of all them accredited by ASHP or Canada. The majority of responders were Saudi 38 (95\%) and 28 (70\%) were male gender and $12(30 \%)$ were female as explored in Table 1. Of responded hospitals; The Established organizational authority for the MUE process and identified responsible individuals and groups at 26 (65\%) of hospitals applied $25 \%-100 \%$ the elements. Developed screening mechanism (indicators) for comprehensive surveillance of the medications use system existed in $24(60 \%)$ hospitals involved $25 \%-100 \%$ the elements. Set priorities for in-depth analysis of important aspects of medications use existed in 24 (60\%) hospitals ultimately $25 \%-100 \%$ used the parts. Inform health-care professionals (and others as necessary) in the practice settings about the objectives and expected benefits of the MUE process exist in 25 (62.5\%) hospitals applied 25\%-100\% the elements. Establish criteria, guidelines, treatment protocols and standards of care for specific medications and medications use processes found in 26 (65\%) hospitals applied 25\%-100\% the elements. Educate healthcare professionals to promote the use of criteria, guidelines, treatment protocols and standards of care existed in 27 (67.5\%) hospitals found applied $25 \%-100 \%$ the elements. Establish mechanisms for timely communication among health-care professionals exist in 23 (57.5\%)

\begin{tabular}{|c|c|c|c|c|c|c|c|c|c|c|}
\hline \multicolumn{3}{|c|}{ Size, ownership and accreditation of respondents } & \multicolumn{2}{|c|}{ Nationality } & \multicolumn{2}{|c|}{ Sex } & \multicolumn{4}{|c|}{ Accreditation } \\
\hline $\begin{array}{c}\text { Hospital size } \\
\text { (Number of staffed } \\
\text { beds) }\end{array}$ & $\begin{array}{l}\text { Number of } \\
\text { hospitals }\end{array}$ & Percentages & Saudi & Non-Saudi & Male & Female & CIBAHI & $\mathrm{JCl}$ & Canada & ASHP \\
\hline \multicolumn{11}{|c|}{ Small } \\
\hline$<50$ & 1 & $2.50 \%$ & $1(2.5 \%)$ & $0(0 \%)$ & $1(2.5 \%)$ & $0(0 \%)$ & $0(0 \%)$ & $0(0 \%)$ & $0(0 \%)$ & $0(0 \%)$ \\
\hline $50-99$ & 6 & $15 \%$ & $6(15 \%)$ & $0(0 \%)$ & $6(15 \%)$ & $0(0 \%)$ & $0(0 \%)$ & $0(0 \%)$ & $0(0 \%)$ & $0(0 \%)$ \\
\hline \multicolumn{11}{|c|}{ Medium } \\
\hline $100-199$ & 7 & $17.50 \%$ & $7(17.5 \%)$ & $0(0 \%)$ & $6(15 \%)$ & $1(2.5 \%)$ & $0(0 \%)$ & $0(0 \%)$ & $0(0 \%)$ & $0(0 \%)$ \\
\hline 200-299 & 8 & $20 \%$ & $7(17.5 \%)$ & $1(2.5 \%)$ & $5(12.5 \%)$ & $3(7.5 \%)$ & $5(25 \%)$ & $2(10 \%)$ & $0(0 \%)$ & $0(0 \%)$ \\
\hline \multicolumn{11}{|c|}{ Large } \\
\hline 300-399 & 7 & $17.50 \%$ & $7(17.5 \%)$ & $0(0 \%)$ & $4(10 \%)$ & $3(7.5 \%)$ & $4(20 \%)$ & $2(10 \%)$ & $0(0 \%)$ & $0(0 \%)$ \\
\hline $400-599$ & 7 & $17.50 \%$ & $6(15 \%)$ & $1(2.5 \%)$ & $5(12.5 \%)$ & $2(5 \%)$ & $6(30 \%)$ & $4(20 \%)$ & $0(0 \%)$ & $0(0 \%)$ \\
\hline $\begin{array}{l}\text { More than or equal } \\
600\end{array}$ & 0 & $0 \%$ & $0(0 \%)$ & $0(0 \%)$ & $0(0 \%)$ & $0(0 \%)$ & $0(0 \%)$ & $0(0 \%)$ & $0(0 \%)$ & $0(0 \%)$ \\
\hline \multicolumn{11}{|c|}{ Very large } \\
\hline Medical cities & 0 & $0 \%$ & $0(0 \%)$ & $0(0 \%)$ & $0(0 \%)$ & $0(0 \%)$ & $0(0 \%)$ & $0(0 \%)$ & $0(0 \%)$ & $0(0 \%)$ \\
\hline $\begin{array}{l}\text { National and } \\
\text { Regional Drug } \\
\text { Information Centers }\end{array}$ & 4 & $10 \%$ & $4(10 \%)$ & $0(0 \%)$ & $1(2.5 \%)$ & $3(7.5 \%)$ & $0(0 \%)$ & $0(0 \%)$ & $0(0 \%)$ & $0(0 \%)$ \\
\hline Missing no-response & 0 & $0 \%$ & $0(0 \%)$ & $0(0 \%)$ & $0(0 \%)$ & $0(0 \%)$ & $20(50 \%)$ & $20(50 \%)$ & $20(50 \%)$ & $20(50 \%)$ \\
\hline Total respondents & 40 & $100 \%$ & $38(95 \%)$ & $2(5 \%)$ & $28(70 \%)$ & $12(30 \%)$ & $20(50 \%)$ & $20(50 \%)$ & $20(50 \%)$ & $20(50 \%)$ \\
\hline Ownership & - & - & - & - & - & - & - & - & - & - \\
\hline MOH-Hospitals & 40 & $100 \%$ & - & - & - & - & - & - & - & - \\
\hline Non-MOH Hospitals & 0 & $0 \%$ & - & - & - & - & - & - & - & - \\
\hline Privates & 0 & $0 \%$ & - & - & - & - & - & - & - & - \\
\hline
\end{tabular}

Table 1: Size, ownership and accreditation of respondents. 
hospitals found used $25 \%-100 \%$ the elements. Initiate the use of MUE criteria, guidelines, treatment protocols and standards of care in the medication-use process exist in 24 (60\%) hospitals found applied $25 \%$ $100 \%$ the elements. Develop and implement plans for improvement of the medications use the method based on MUE findings (if indicated) and assess the effectiveness of action taken and document improvements exist in 25 (62.5\%) hospitals found applied 25\%-100\% the elements. Incorporate improvements into criteria, guidelines, treatment protocols and standards of care when indicated exist in 24 (60\%) hospitals found applied $25 \%-100 \%$ the elements. Repeat the cycle of planning, evaluating and taking action for ongoing improvements in medications use processes Repeat the cycle of planning, evaluating and taking action for ongoing improvements in medications use methods exist in $24(60 \%)$ hospitals found applied $25 \%-100 \%$ the elements. Regularly assesses the effectiveness of the MUE process itself and makes needed improvements exist in $24(60 \%)$ hospitals found used $25 \%-100 \%$ the items as explored in Table 2.

\section{Discussion}

The General Administration of Pharmaceutical Care released more than thirty pharmacy practice, clinical pharmacy services and pharmacy management programs $[22,23]$. It was during the implementation of pharmacy strategic plan at Ministry of Health in Kingdom of Saudi Arabia. One of measuring of pharmacy indicators to follow up the implementation of pharmacy strategic plan was Drug Utilization Evaluation or Medication Utilization
Evaluation. The DUE system applied for several projects to measure the adherence of guidelines including pharmacy pain management, Antimicrobial stewardship program and pharmacy anticoagulation program [24-26]. The pharmacy administration formulated central DUE committee with membership representatives from several regions $\mathrm{MOH}$ regions. The committee updated the method of data collation information from retrospective collection through medical records to prospective coalition information by using physicians Order sheet. The form as prescription filled by practitioners with original copy in the medical patient profile, second copy sent to inpatient pharmacy for the unit dose distribution system and copy to drug information centers to fill electronic form through survey monkey for analysis. The task force committee finished from several projects including vancomycin physician order, Tigecycline physician order and Intravenous Paracetamol. The authors investigated by a National Survey of Drug Information Centers with emphasis on drug utilization evaluation system at $\mathrm{MOH}$ hospitals. The finding not completed with half of the elements implemented. The results showed less than what's finding in studies by an old study by Matuszewski, Karl A or new studies by Rosenberg JM, et al. conducted in 2004 and 2009 [12,14,15]. The reasons behind that were the programs newly established at $\mathrm{MOH}$ hospitals and few clinical pharmacists implemented the program. It needs some time until full implementation of the DUE system at drug information centers. Others are finding challenges to compare due insufficient investigations to compare with them. The network drug

\begin{tabular}{|c|c|c|c|c|c|c|c|}
\hline Answer Options & 1 & 2 & 3 & 4 & 5 & $\begin{array}{c}\text { Rating } \\
\text { average }\end{array}$ & $\begin{array}{l}\text { Response } \\
\text { count }\end{array}$ \\
\hline Established organizational authority for the MUE process and identify responsible individuals and groups. & 14 & 4 & 8 & 5 & 9 & 2.78 & 40 \\
\hline $\begin{array}{l}\text { Developed screening mechanism (indicators) for comprehensive surveillance of the medication-use } \\
\text { system. }\end{array}$ & 16 & 5 & 7 & 4 & 8 & 2.58 & 40 \\
\hline Set priorities for in-depth analysis of important aspects of medications-use. & 16 & 5 & 8 & 3 & 8 & 2.55 & 40 \\
\hline $\begin{array}{l}\text { Inform health-care professionals (and others as necessary) in the practice settings about the objectives } \\
\text { and expected benefits of the MUE process. }\end{array}$ & 15 & 5 & 8 & 2 & 10 & 2.68 & 40 \\
\hline $\begin{array}{l}\text { Establish criteria, guidelines, treatment protocols, and standards of care for specific medications and } \\
\text { medication-use processes. These should base on sound scientific evidence from the medical and } \\
\text { pharmaceutical literature. }\end{array}$ & 14 & 6 & 7 & 4 & 9 & 2.7 & 40 \\
\hline $\begin{array}{l}\text { Educate healthcare professionals to promote the use of criteria, guidelines, treatment protocols, and } \\
\text { standards of care. }\end{array}$ & 13 & 4 & 8 & 5 & 10 & 2.88 & 40 \\
\hline Establish mechanisms for timely communication among health-care professionals. & 16 & 5 & 8 & 3 & 7 & 2.49 & 39 \\
\hline $\begin{array}{l}\text { Initiate the use of MUE criteria, guidelines, treatment protocols, and standards of care in the medication- } \\
\text { use process }\end{array}$ & 15 & 5 & 7 & 4 & 8 & 2.62 & 39 \\
\hline Collect data and evaluate care. & 14 & 5 & 6 & 8 & 6 & 2.67 & 39 \\
\hline $\begin{array}{l}\text { Develop and implement plans for improvement of the medication-use process based on MUE findings (if } \\
\text { indicated).Assess the effectiveness of action taken and document improvements. }\end{array}$ & 14 & 5 & 6 & 9 & 5 & 2.64 & 39 \\
\hline $\begin{array}{l}\text { Incorporate improvements into criteria, guidelines, treatment protocols, and standards of care when } \\
\text { indicated. }\end{array}$ & 15 & 6 & 6 & 5 & 7 & 2.56 & 39 \\
\hline $\begin{array}{l}\text { Repeat the cycle of planning, evaluating, and taking action for ongoing improvements in medication-use } \\
\text { processes. }\end{array}$ & 15 & 5 & 7 & 5 & 7 & 2.59 & 39 \\
\hline Regularly assess the effectiveness of the MUE process itself and make needed improvements. & 15 & 4 & 9 & 6 & 5 & 2.54 & 39 \\
\hline \multicolumn{7}{|l|}{ answered question } & 40 \\
\hline \multicolumn{7}{|l|}{ skipped question } & 0 \\
\hline \multicolumn{7}{|l|}{ 1: DIC is NOT applying the elements 2 : DIC is applying $25 \%$ of the elements } & \multirow{3}{*}{-} \\
\hline \multicolumn{7}{|l|}{ 3: DIC is applying $50 \%$ of the elements. 4 : DIC is applying $75 \%$ of the elements } & \\
\hline \multicolumn{7}{|l|}{$5:$ DIC is applying $100 \%$ of the elements } & \\
\hline
\end{tabular}

Table 2: Drug Information Centers (DIC) had process for Medication-Use Evaluation. 
Citation: Alomi YA, Alghamdi SJ, Alattyh RA (2017) National Survey of Drug Information Centers Practice in Saudi Arabia: Medication-Use Evaluation System at Ministry of Health Hospitals. J Pharmacovigil 5: 245. doi:10.4172/2329-6887.1000245

information centers need education and training of DUE system and close monitoring and follow-up of the services with a repeat the survey in the nearest future at drug information centers at $\mathrm{MOH}$ hospital in Kingdom of Saudi Arabia.

\section{Conclusion}

There was a moderate application of Medication-Use Evaluation in drug information centers practice. Revising the pharmacy strategic planning including Medication-Use Evaluation system is required. Targeting educate and trainee the drug information pharmacists, with distributing the impact results of the program will improve application DUE system at $\mathrm{MOH}$ hospitals through a network of drug information centers in Kingdom of Saudi Arabia.

\section{References}

1. Phillips M, Gayman J, Todd M. ASHP guidelines on medication-use evaluation. American Society of Health-system Pharmacists. Am J Health Syst Pharm 53: 1953-1955.

2. Doherty P, Kirsa S, Chao S, Wiltshire S, McKnight D, et al. (2004) SHPA standards of practice for drug use evaluation in australian hospitals. J Pharm Pr Res 34: 220-223.

3. Medication Management (2015) In: National Hospital Standards. 2nd edn. Saudi Central Board for Accreditation of Healthcare Institutionsp, p:194-211.

4. Comprehensive Accreditation Manuals. Joint Commission Resources.

5. Alomi YA, Almudaiheem HY (2016) Adherence to vancomycin therapeutic guidelines at ministry of health hospital in saudi arabia. Value Heal 19: A486.

6. Alomi YA, Almudaiheem HY(2017) Clinical outcomes of vancomycin therapeutic monitoring services at Ministry of Health Hospital in Saudi Arabia. In: Value Health 19: A42.

7. Alomi YA, Almudaiheem HY (2017) Aminoglycoside therapeutic monitoring compliance at Ministry of Health Hospital In Saudi Arabia. In: Value Health A40-A41.

8. Alomi, Yousef (2001) Drug Utilization Evaluation of Albumin. In: Saudi Pharmaceutical Society.

9. Alomi, Yousef (2001) Drug Utilization Evaluation of Immunoglobulin. In: Saudi Pharmaceutical Society.

10. Alomi YA, AL- Mudaiheem H, Alsharfa A, Albassri H, Alonizi K, et al. (2016) National Drug Information Center Services through Ministry of Health Hotline Calling Center (937) in Saudi Arabia. Adv Pharmacoepidemiol Drug Saf 5:198.
11. Taggiasco N, Sarrut B, Doreau CG (1992) European survey of independent drug information centers. Ann Pharmacother 26: 422-428.

12. Matuszewski KA, Windisch PA (1998) Drug information activities in academic health centers: A 1996 Survey. Drug Inf J 32: 539-546.

13. Lim LY, Chui WK (1999) Pharmacist-operated drug information centers in singapore. J Clin Pharm Ther 24: 33-42.

14. Rosenberg JM, Koumis T, Nathan JP, Cicero LA, McGuire H (2004) Current status of pharmacist-operated drug information centers in the united states. Am J Heal Pharm 61: 2023-2032.

15. Rosenberg JM, Schilit S, Nathan JP, Zerilli T, Mcguire H (2009) Update on the status of 89 drug information centers in the united states. Am J Heal Pharm 66: $1718-1722$.

16. Alexandra M, Manosalva N, Lopez Gutierrez JJ, Canas M (2016) Drug information centers: An overview of the concept. Rev Colomb Cienc Quim Farm 45: 243-255

17. Vidotti CCF (2004) Drug information centers in developing countries and the promotion of rational use of drugs: A viewpoint about challenges and perspectives managerial skills role of dics in. Int Pharm J 18: 21-23.

18. Alamri SA, Ali R, Jaizani A, Naqvi AA, Safer M, Ghamdi MSA (2017) Assessment of drug information service in public and private sector tertiary care hospitals in the eastern province of saudi arabia. Pharmacy (Basel) 5 pii: E37.

19. Vernon G, Dvorkin L, Vidotti CCF, Woods D (2005) Requirements for Drug Information Centres. FIP Pharmacy Information Section.

20. Ghaibi S, Ipema HGM (2015) ASHP guideline on the pharmacist's role in providing drug information. Am J Heal Pharm 72: 573-577.

21. Ministry of Health GPCD (2014) ThCe minimum standard of Drug Information Center in KSA. Ministry of Health, Saudi Arabia.

22. Alomi YA, Alghamdi SJ, Alattyh RA (2015) Strategic plan of genera administration of pharmaceutical care at Ministry of Health in Saudi Arabia 2012-2022. J Pharm Pharm Scien 1: 1-8.

23. Alomi YA (2015) National pharmacy practice programs at ministry of health in Saudi Arabia. JPharm Pharm Scien 1: 17-18.

24. Alomi YA (2017) National pharmacy pain management program at ministry of health in Saudi Arabia. J Pharmacol Clin Res 3: 7.

25. Alomi YA (2017) National antimicrobial stewardship program in Saudi Arabia Initiative and the future. Open Access J Surg 4: 7.

26. Alomi YA (2017) National pharmacy anticoagulation program at ministry of health in saudi arabia. BAOJ Pharm Sci 3: 3-7. 